\title{
PROBLEMAS RELACIONADOS CON LAS ENCUESTAS PREELECTORALES DESDE UNA PERSPECTIVA COMPARADA
}

\author{
Michael W. Traugott \\ Universidad de Michigan
}

\begin{abstract}
RESUMEN: Las encuestas de opinión pública son uno de los pilares de la democracia moderna y le brindan a la ciudadanía voz en los debates sobre leyes, políticas y regulaciones. Sin embargo, existen problemas prácticos al momento de realizar encuestas científicas. Algunos se relacionan con las tecnologías para recabar datos; otros con la capacidad de contactar a los encuestados en un lapso cada vez más reducido; las complejidades de diseñar preguntas que midan las opiniones y comportamientos de las personas de la manera menos sesgada posible; y las modificaciones en los sistemas electorales, lo que afecta directamente la precisión de las encuestas preelectorales. Este artículo da cuenta de algunos errores de estimación que se han producido en este tipo de encuestas en distintas partes del mundo y analiza algunas de sus posibles causas.
\end{abstract}

Palabras ClaVE: elecciones, encuestas, opinión pública, medios de comunicación, problemas metodológicos.

RECIBIDO: octubre 2014; ACEPTADO: diciembre 2014.

Michael W. Traugott. PhD en ciencias políticas en la Universidad de Michigan, Ann Harbor. Profesor en la misma universidad e investigador en el Institute for Social Research de ese claustro. Ha escrito, coescrito o editado nueve libros y cerca de 40 artículos académicos. Entre otras materias, ha investigado el uso y la validez de las encuestas políticas, la predicción de elecciones y los sondeos de opinión pública utilizados en los medios de comunicación. Email: mtrau@umich.edu 


\title{
PROBLEMS WITH PRE-ELECTION POLLS IN COMPARATIVE PERSPECTIVE
}

\begin{abstract}
Public opinion polls are one of the most important foundations of modern democracy and give citizens a voice in the debates on laws, policies and regulations. However, there are practical problems in taking scientific polls. Some of these involve the data-gathering technologies. Others relate to the ability to reach sampled respondents in an increasingly shorter period of time, to the complexities of designing questions that measure the opinions and behavior of individuals with the least bias possible, and to the changes in the electoral systems, which have a direct impact on the accuracy of pre-election polls. This article discusses some errors in estimation that have occurred in this type of polling in different parts of the world and analyzes some of the possible causes.
\end{abstract}

KEYWORDs: elections, surveys, public opinion, communications media, methodology issues.

ReCEIVED: October 2014; ACCEPTED: December 2014.

as encuestas de opinión pública son uno de los pilares de la democracia moderna y constituyen un elemento que le brinda a la ciudadanía una voz independiente en los debates sobre leyes, políticas y regulaciones. Si consideramos la representación como un principio fundamental de la democracia, medir la percepción de las personas respecto de temas relevantes de la contingencia o determinar sus preferencias en términos de la acción gubernamental son formas claves de asegurar la participación ciudadana en la gestión pública (Gallup y Rae 1940; Lavrakas y Traugott 2000; Clawson y Oxley 2012). Los ciudadanos tienen varias opciones para expresar sus puntos de vista, como, por ejemplo, escribir cartas a los periódicos, publicar comentarios en blogs, realizar manifestaciones y huelgas, y sufragar. Todas poseen sesgos implícitos que provienen del interés que motiva a los actores a participar en relación con aquellos que no lo hacen. Sin embargo, las encuestas de opinión pública, cuando se basan en métodos científicos bien aplicados y, más específicamente, en métodos fiables de muestreo probabilístico, constituyen una de las formas más eficaces de asegurar que todos los puntos de vista estén representados en relación con su proporción en una población y no en función del grado de entusiasmo o compromiso de los ciudadanos con una causa (Traugott 2004). 
Existen problemas prácticos al momento de realizar encuestas científicas. Algunos se relacionan con la disponibilidad de tecnologías para recabar datos, como los teléfonos y los computadores; otros con la capacidad de contactar a los encuestados en el lapso cada vez más reducido en que las encuestas suelen realizarse en la actualidad; y las complejidades resultantes de diseñar preguntas neutras que midan las actitudes, opiniones y comportamientos de las personas de la manera menos sesgada posible. El desarrollo de metodologías de encuesta científicas adecuadas es un proceso permanente, que consiste en adaptar un conjunto establecido de procedimientos científicos a un entorno específico. El principio básico que guía la valoración de cualquier resultado de una encuesta y su relevancia es la transparencia a la hora de divulgar la metodología empleada, para que consumidores informados puedan evaluar los datos en el contexto en que éstos fueron obtenidos.

La imagen de la industria en su conjunto, que abarca tanto las investigaciones de mercados como las encuestas sociales, se basa en el desempeño de las encuestas preelectorales, pues, de todos los temas que son sometidos a la opinión pública, ningún otro tiene la validación externa que proviene del resultado mismo de la elección. Aun cuando muchos argumentan que las encuestas son sólo fotografías de actitudes o comportamientos esperados en un momento específico (Rothschild y Rivers 2012), los periodistas describen los sondeos realizados en los días previos a las elecciones como proyecciones del resultado; y los agregadores de datos las utilizan en los modelos estadísticos para predecir, con una alta probabilidad, el resultado de una elección (Gelman 2013). Si las estimaciones resultan muy certeras, las empresas de opinión pública se atribuyen el mérito de sus metodologías para promover comercialmente sus empresas.

Todos los países en los que se han llevado a cabo encuestas preelectorales se han encontrado ocasionalmente con estimaciones que han diferido del resultado final por un margen inaceptable. En algunas oportunidades éstas sugirieron un falso vencedor, como en el caso de "Dewey vence a Truman" (Mosteller et al. 1949) o la anticipada victoria de Barack Obama en la primaria de New Hampshire, en 2008 (AAPOR 2009), pero, por lo general, los errores de estimación involucran márgenes muy amplios o pequeños de la victoria. Cuando surgen estos problemas, se organizan comités o reuniones para discutir sobre las fuentes de 
los errores. Estas instancias podrían ser la oportunidad para que encuestadores académicos y comerciales colaboren en estudios que permitan determinar la causa de los errores y la forma de remediarlos, pero estos estudios rara vez se concretan porque los investigadores de opinión pública no desean divulgar los pormenores de su metodología que consideran parte de su propiedad y de su ventaja competitiva. También sucede que para justificar los errores en las estimaciones los encuestadores recurren a un típico conjunto de explicaciones ("los votantes cambiaron de opinión", "las personas que se deciden en el último minuto se movieron en determinada dirección" o "los encuestados nos mintieron") que difiere sustancialmente del utilizado por los académicos, que se basan principalmente en explicaciones metodológicas, tales como características de la muestra, ponderaciones o modelos de votante probable (Durand 2010). Producto de lo anterior, el proceso de descubrir las fuentes de los errores de estimación es lento e incierto, y nuestro conocimiento sobre cómo lidiar con ellos es limitado.

Estos problemas han surgido en todas las democracias en que se realizan encuestas preelectorales. En este artículo, entregaremos algunos ejemplos de países en los cuales se produjeron errores de estimación en diferentes elecciones y analizaremos sus posibles causas. Para ello, contrastaremos la forma en que los problemas fueron investigados y abordados. Algunos estuvieron relacionados con la adecuación de los modelos de comportamiento electoral y en cómo estos cambiaron - si tal fue el caso- cuando factores institucionales afectaron el proceso de votación. La mayoría de los problemas se relacionan con temas metodológicos relativamente claros, cuyos efectos se identificaron en varios análisis post hoc, a pesar de que sólo en algunos casos se han realizado experimentos para evaluar hipótesis específicas sobre sus posibles causas. En las conclusiones, se analizan posibles vías para mejorar la metodología de encuestas preelectorales en general y en Chile.

\section{EL ROL DE LAS ENCUESTAS EN UNA DEMOCRACIA}

Las encuestas cumplen funciones claves en una democracia. Permiten evaluar las reacciones de los ciudadanos frente a las posturas que los candidatos toman respecto de diversos temas y frente a los programas de gobierno desplegados durante las campañas políticas. 
Si se realizan en más de una oportunidad durante una campaña, estos sondeos pueden medir la evolución del apoyo hacia los candidatos y los partidos. Pueden efectuarse de manera global con muestras representativas recurrentes o, en casos más puntuales, pueden consistir en sucesivas entrevistas a los mismos encuestados, lo que constituye la mejor manera de medir cambios a nivel individual. Después de una elección, las encuestas pueden servir para exigir cuentas a las autoridades electas respecto de posiciones que asumieron durante sus campañas. También se utilizan para evaluar la opinión pública respecto de temas o políticas que no fueron abordados durante el período preelectoral. Esto puede deberse a que los candidatos no pusieron el énfasis en dichos temas o, más posiblemente, porque acontecimientos inesperados colocaron nuevos temas en la agenda. Las encuestas y la difusión de sus resultados son también importantes, porque informan a los ciudadanos respecto de lo que otros opinan sobre políticas relevantes o sobre cómo están evaluando a candidatos y cargos electos (Traugott 1992, 2004). Las encuestas representan una forma clave de informar sobre la opinión pública a todos los ciudadanos interesados.

Un factor importante que incide en la forma en que los resultados de las encuestas son anunciados en los medios de comunicación tiene que ver con la diferencia entre aquellas consultas realizadas durante el ejercicio rutinario del poder de un gobierno o régimen y aquellas llevadas a cabo antes de unas elecciones. Las encuestas rutinarias son realizadas y difundidas en función de importantes acontecimientos o etapas de un gobierno, como la inauguración de un nuevo mandato, los cien primeros días en el poder, un discurso de alta trascendencia de un líder nacional o en torno a eventos relevantes relacionados con asuntos internos o de política exterior. Hoy es muy usual mantener un seguimiento periódico del índice de aprobación del gobierno a través de evaluaciones de la gestión del Presidente, el Primer Ministro o el Parlamento. Esas encuestas arrojan resultados recurrentes o consistentes en la evaluación del desempeño de las autoridades, que permiten establecer ciertos patrones de conducta en la opinión pública. Por ejemplo, los expertos generalmente observan que la popularidad de un líder gubernamental alcanza su más alto nivel cuando él o ella asume sus funciones, fenómeno conocido como "luna de miel" (Grossman y Kumar 1981). Luego viene una etapa de declive a lo largo del 
ejercicio del poder, que va de la mano con un marcado sesgo partidista. Al inicio del mandato, los adherentes de los grupos políticos suelen dar el beneficio de la duda a los nuevos líderes electos, deseándoles éxito en su gestión. Una vez que se han formulado e implementado determinadas políticas, los grupos opositores retiran paulatinamente su apoyo y los ciudadanos independientes pueden también eventualmente cambiar de opinión (Eisenstein y Wittig 2000).

Los analistas de encuestas de opinión pública también advierten que esta tendencia decreciente en el apoyo a las autoridades se ve definida de manera distintiva según la coyuntura económica o ante la eventualidad de crisis profundas, especialmente en materia de relaciones internacionales. Cuando la situación general del país es positiva o la economía repunta, la caída en el apoyo popular es usualmente moderada. Cuando la situación económica se deteriora, este declive suele ser acelerado. Cuando ocurre un desafío relevante en materia de política internacional, los ciudadanos tienden a redoblar su apoyo a las autoridades electas y su popularidad aumenta como un "efecto de movilización" (Mueller 1970). Cuando ocurre un hecho bochornoso, la adhesión popular cae en algunos casos de manera estrepitosa. En cualquiera de estos escenarios, puede que se requiera un cierto tiempo antes de que la opinión pública vuelva a su ciclo de conducta habitual.

Las encuestas preelectorales son un tipo de sondeo de opinión que tiene un atractivo especial para los medios informativos y la forma en que éstos cubren las elecciones. Son un elemento clave en la pauta noticiosa por su incidencia en el control del poder en una democracia. Desde una perspectiva mediática, también ocurren dentro de un lapso definido con una fecha de inicio y de término (día de las elecciones), lo que les permite a los medios informativos diseñar un plan de cobertura y asignarle recursos, un plan sujeto a revisiones periódicas en función de la evolución de la campaña electoral y de su grado de competitividad. Las campañas también traen consigo una serie de figuras públicas, como los candidatos y sus asesores directos, quienes suelen estar disponibles para entrevistas y para ser citados en crónicas y artículos noticiosos. Las campañas implican enfrentamiento entre las fuerzas que compiten, lo que constituye un componente central de la relevancia noticiosa, pero las elecciones producen un claro ganador y perdedor que se dan a conocer el día de las elecciones o poco después. Ello permite 
también cerrar adecuadamente el ciclo en ese momento. Después de las elecciones, las encuestas pueden utilizarse como parte de la cobertura mediática para describir los desafíos que enfrenta el nuevo gobierno y los niveles de adhesión en diferentes ámbitos.

\section{BREVE HISTORIA DE LAS ENCUESTAS ELECTORALES DE LOS MEDIOS DE COMUNICACIÓN}

Los medios de comunicación tienen un gran interés en la contingencia política y en buscar nuevas formas de darle cobertura; de ahí su permanente preocupación en informar sobre la percepción pública de los problemas. Despliegan diversas estrategias para presentar dicha información, con entrevistas al "hombre de la calle", estimaciones del número de personas que acuden a manifestaciones públicas o que protestan cuando los candidatos hacen apariciones públicas. Los precursores de las encuestas científicas en los Estados Unidos se remontan a inicios del siglo diecinueve bajo la forma de "sondeos de opinión". En aquella época se vendían alimentos para mascotas o palomitas de maíz en envases característicos que representaban a un candidato o partido involucrado en una elección (Herbst 1993). Los medios de comunicación informaban cuál tipo de envase tenía mayores ventas, lo que se interpretaba como un indicador relativo de apoyo.

El advenimiento de la era de los sondeos de opinión modernos generalmente se asocia con la elección presidencial de 1936 de los Estados Unidos. En las cinco contiendas electorales anteriores, una importante revista nacional — The Literary Digest - había recopilado información acerca de las preferencias de los votantes estadounidenses enviando por correo millones de tarjetas postales a ciudadanos cuyos nombres provenían de listas de dueños de automóviles, abonados a teléfonos fijos y similares. Basándose en numerosas respuestas de un pequeño porcentaje de remitentes, la revista había logrado predecir con éxito el resultado de todas las elecciones presidenciales desde 1916 hasta 1932. Utilizaron la misma metodología en la elección de 1936, pero el país se encontraba inmerso en la Gran Depresión y las falencias de dicha metodología eran evidentes para algunos, entre ellos George Gallup, un investigador de mercados en una destacada agencia de publicidad. Basándose en su experiencia en una campaña electoral en 
Iowa en apoyo a su suegra, Gallup había desarrollado una metodología de muestreo y recolección de datos más científica para medir la opinión pública (Chaffee 2000).

Tras varios movimientos que lo trasladaron a Nueva York, Gallup decidió aplicar su metodología a gran escala, desafiando a The Literary Digest. Como empresario, sabía cuán necesario era procurarse un rostro público para su nuevo emprendimiento; para ello, se asoció con The Washington Post en torno a un proyecto de encuestas para la elección de 1936. Antes de la cita electoral, Gallup describió las falencias de la metodología de Digest y por qué esta fallaría en sus resultados; presentó su propia metodología para generar una estimación basada en sólo 50 mil entrevistas y le garantizó al Post que sus predicciones serían más acertadas, de lo contrario, no cobraría por su servicio. El Digest sugirió que Alf Landon ganaría las elecciones, mientras que Gallup se inclinaba por Franklin Roosevelt; y, como dicen, lo demás es historia (Squire 1988). En 1938, The Literary Digest fue absorbido por otra empresa en un proceso de fusión.

Otros dos personajes fueron claves en el advenimiento de las técnicas de encuestas en los Estados Unidos, y cada uno estaba asociado con un medio de comunicación que era el rostro visible para sus sondeos de opinión. El primero es Elmo Roper, que realizaba encuestas para la revista Fortune. El otro es Archibald Crossley, que estuvo brevemente asociado con The Literary Digest y posteriormente con los periódicos de William Randolph Hearst. Él desarrolló una metodología para medir los índices y las preferencias de sintonía radial. Gallup, Roper y Crossley fueron empresarios exitosos en el ámbito de las investigaciones de mercados, que amasaron fortunas con sus empresas, pero entendían la necesidad de tener una presencia visible para atraer clientes. Sus estudios sobre opinión pública — y sus sondeos preelectorales, en particular - eran la clave de esta estrategia y de la consolidación de su éxito comercial. Sus asociaciones con medios de comunicación les aseguraron notoriedad pública, y su éxito general en las predicciones de resultados electorales les confirió credibilidad a sus metodologías y empresas.

La validación externa de las encuestas preelectorales mediante el resultado de las elecciones generó problemas al rubro en 1948, cuando las principales empresas de sondeos predijeron que Dewey derrotaría a Truman, candidato en el cargo, lo que no sucedió (Likert 1948, 
Mosteller et al. 1949). Se procedió a una revisión sistemática de los procedimientos y los datos de las encuestas, y se descubrió una serie de fallas metodológicas como posibles causas del error, entre las que cabe destacar el uso de muestras por cuota en lugar de métodos probabilísticos, ya que generó una sobrerrepresentación de encuestados con nivel socioeconómico más elevado que el electorado en su conjunto y en un sesgo a favor del Partido Republicano, tal como en el caso de la encuesta de 1936 de The Literary Digest (Squire 1988). El problema medular fue dejar la selección de los encuestados en manos de los encuestadores.

Sin embargo, también se produjeron problemas logísticos que limitaron la capacidad de los encuestadores para detectar cambios de último momento a favor de Truman. Estas encuestas se realizaron a través de entrevistas presenciales, consideradas como una técnica adecuada para establecer un vínculo con encuestados no familiarizados con las entrevistas, en una época en que las empresas de estudios de opinión se encontraban en una fase embrionaria. En términos administrativos, el trabajo en terreno duraba aproximadamente un mes, período necesario para enviar cuestionarios por correo a los supervisores en terreno, quienes los distribuían a los encuestadores para que realizaran las entrevistas; estos, a su vez, los enviaban de vuelta a sus supervisores, que los remitían a la oficina central. Las entrevistas realizadas eran procesadas y analizadas. En el caso de Gallup, él lograba, a partir de una encuesta, producir suficiente material para generar columnas quincenales en un período durante un mes. Esto podía ser eficaz para evaluar la opinión pública sobre una serie de temas, pero era insuficiente para detectar cambios de último minuto en una contienda presidencial muy reñida.

El crecimiento de los sondeos como un componente central de las noticias — primero en el ámbito político y luego en otros rubros noticiosos - fue producto de varios factores. Con la introducción de la telefonía de línea fija en la casi totalidad de los hogares de los Estados Unidos, la modalidad de entrevista comenzó a cambiar. A esta innovación tecnológica le siguió poco después la introducción del computador personal. En los años sesenta, las grandes empresas de comunicación masiva se percataron de que no necesitaban apoyarse en empresas como Gallup para diseñar y realizar sus encuestas de opinión. A través de iniciativas conjuntas entre canales de televisión y los principales periódicos metropolitanos — como CBS News y The New York Times o ABC 
News y The Washington Post- los medios de comunicación comprendieron que podían diseñar y realizar sus propias encuestas telefónicas. Los periódicos contaban con centros telefónicos disponibles por las tardes en sus departamentos de avisos clasificados y sus socios tenían una gran experiencia técnica en materia de muestreo y análisis de datos.

Hubo importantes ventajas y desventajas asociadas a estos dos modos de obtención de datos en los sondeos preelectorales. Cuando las entrevistas eran realizadas en directo, el entrevistador podía entregarle al encuestado un "voto secreto" para ser completado y depositado en un sobre o "urna secreta", lo que le daba un aire de privacidad y confidencialidad que no existe cuando se le pide a un encuestado que manifieste en voz alta su opción de voto durante una entrevista telefónica. Esta potencial ventaja de las entrevistas presenciales se ve contrarrestada por el tiempo que requiere reunir entrevistas personales durante una campaña electoral. El principal problema es que un evento que acontece en la campaña una vez que se ha iniciado el proceso de entrevistas en terreno puede invalidar la información obtenida desde los encuestados antes de esa fecha. Esto sucedió en Chile, en 2013, cuando la coalición de partidos de derecha cambió dos veces de candidato después de la selección inicial, lo que llevó al Centro de Estudios Públicos (CEP) a tener que suspender una encuesta que estaba realizando en terreno en ese momento.

Las entrevistas telefónicas suponen un tiempo mucho más acotado de trabajo en terreno, por lo general entre tres y cinco días; ello permite entrevistar hasta la jornada previa a las elecciones (cuando la ley lo autoriza), lo que les brinda a los encuestadores la oportunidad de medir cambios finales en las preferencias o evaluar reacciones a eventos de último momento. En la contienda electoral de 2013 en Chile, una empresa que hubiera optado por encuestas telefónicas podría haber desechado sus datos anteriores y haber rápidamente reiniciado su proceso de entrevistas cuando se anunció el cambio de candidato. Todos los estudios de opinión implican cálculos de costo-beneficio como éstos y los sondeos preelectorales no son diferentes en términos de sus requisitos y características peculiares.

Esta innovación fue también importante desde una perspectiva noticiosa, porque estas empresas podían utilizar sus propios criterios de relevancia informativa al momento de diseñar las encuestas y determinar el momento óptimo para llevar un estudio a terreno. El uso del 
teléfono redujo igualmente el período de trabajo de campo de meses a días, disminuyendo de paso la posibilidad de que determinados acontecimientos de la coyuntura pudieran invalidar la veracidad de hallazgos particulares. Durante ese período, es importante también señalar que los periódicos y los programas televisivos vespertinos compartían los mismos momentos de cierre, los mismos deadlines. Al final de la última jornada de entrevistas telefónicas, estaba convenido que el socio televisivo recibiría el primer relato periodístico para difundirlo de manera sucinta. Simultáneamente, los periódicos del día siguiente preparaban una crónica más detallada sobre los resultados. Con este esquema, se silenciaron algunas de las presiones competitivas tradicionales, aunque éstas han aumentado desde el advenimiento del ciclo permanente de 24 horas de noticias.

La creciente disponibilidad de encuestas provocó cambios en los estilos de divulgación. Los mismos factores que determinaron el interés en que se cubran las elecciones también influyeron en la forma en que éstas eran cubiertas. Se produjo un mayor interés en saber quién lideraba en las preferencias y por qué margen. Los periodistas también se centraron en la dinámica de la contienda - quién iba ganando o perdiendo-, y esta tendencia era sustentada por sondeos que medían el desempeño relativo de los candidatos. Estas fuerzas produjeron un fenómeno conocido como el periodismo de "carrera de caballos", y con él se produjo un incremento en la cantidad de breves encuestas periódicas conocidas como "encuestas de seguimiento", las que se centraban en preguntas directas tendientes a medir la posición relativa de los candidatos. Esto produjo un nuevo énfasis en la cobertura periodística de las campañas y elecciones (Iyengar et al. 2004; Patterson 1993, 2005; Rosenstiel 2005).

En el siguiente periodo, especialmente en los últimos 20 años, diversos fenómenos económicos han afectado a los medios de comunicación y alterado el rol de los sondeos de opinión en la producción de noticias. Uno de los más visibles es el aumento en la cantidad de canales noticiosos, atribuible en primer lugar al auge de internet. Las empresas mediáticas no sólo tienen que asegurarse de tener una presencia significativa en la web, sino que además deben operar en un escenario con nuevos canales de todo tipo para noticias y contenidos informativos como blogs y sitios web de orientación política. Estos han generado más presión por una actualización permanente de conte- 
nidos, lo que ha vuelto la demanda de contenidos nuevos un fenómeno casi irrefrenable.

Al mismo tiempo, han surgido un sinnúmero de nuevas presiones económicas que se traducen en recortes presupuestarios para la obtención de noticias y las operaciones de sondeo de opinión que forman parte de ellas. El primer efecto negativo fue, para los periódicos, la pérdida de ingresos asociados a avisos clasificados, pero las presiones económicas se han hecho sentir en todos los ámbitos de la industria. También se han producido cambios en la contratación de personal y en los estilos de periodismo. La reducción en el número de reporteros en la mayoría de los medios de comunicación se ha traducido en una menor especialización y en contenidos de interés más general. Cada día son más las empresas noticiosas que compran contenidos de servicios de cable o de otros proveedores de servicios. Esto significa que muchas empresas han tenido que reducir su número de especialistas en opinión pública, e incluso eliminar sus operaciones de sondeos, sobre todo ante la presencia de sitios web que se especializan en la recopilación y difusión de datos sobre opinión pública.

Otra importante tendencia de este periodo es una caída regular en las tasas de respuesta en los sondeos. Una investigación realizada por De Leeuw y De Heer (2002) compiló datos de no respuestas de 16 países y analizó sus diferencias por tipo de encuesta y en diferentes períodos temporales. Hallaron que las bajas en las tasas de respuesta eran manifiestas en todos los países y en todos los tipos de encuesta a lo largo del tiempo. Al separar las fuentes de no respuesta en dos componentes - no contacto y rechazos-- observaron que no había diferencias en las tasas de contacto y que eran las tasas de rechazo las que se habían incrementado con el tiempo y que diferían según los países. Las diferencias en las tasas de rechazo estaban inversamente relacionadas con los indicadores socioeconómicos en los diferentes países, pero se reducían cuando existía una supervisión y un monitoreo de los entrevistadores.

Otros investigadores sugieren que las no respuestas no deben ser utilizadas como un indicador global de la calidad de las encuestas. En la metodología de Total Survey Error (TSE, lo que podría traducirse como Error Global de la Encuesta), para evaluar la calidad de una encuesta existen varias instancias en las que pueden introducirse errores significativos en su proceso de elaboración. A pesar de que Groves (2006) ha 
realizado el mejor planteamiento teórico sobre las consecuencias potenciales de la no respuesta en términos de resultados sesgados en una encuesta, él también ha participado en diversos estudios en los cuales esto ocurre y en otros en que no ocurre. Su investigación sugiere que lo anterior no es tan grave en encuestas preelectorales como sí en otros ámbitos, pues los factores que sugieren una propensión a votar son los mismos que sugieren una propensión a participar en encuestas políticas (Curtin et al. 2000; Keeter et al. 2000; Merkle y Edelman 2002). En otras palabras, las personas con menor interés en la política o en votar son las más propensas a negarse a participar en encuestas. A pesar de que esto puede producir un sesgo en algunas encuestas hacia los puntos de vista de los ciudadanos más informados y políticamente comprometidos, es probable que no tenga mucho impacto en los modelos de votante probable de las encuestas preelectorales.

En resumen, las encuestas preelectorales son parte integrante de la cobertura política en muchas empresas de noticias en el mundo. Éstas refuerzan la ya establecida tendencia de los medios de comunicación de darle énfasis a la cobertura política, y lo hacen en una forma particular. Las empresas de investigación de mercado y los encuestadores buscan socios en los medios de comunicación para generar y ampliar la visibilidad de sus empresas. A pesar de que, por lo general, sus sondeos preelectorales les generan, en el mejor de los casos, bajos ingresos, la visibilidad y el acierto de sus predicciones atraen clientes hacia el componente comercial de sus empresas. De esta forma, existe una fuerte relación simbiótica entre los encuestadores y las empresas de noticias que opera en beneficio mutuo. Al mismo tiempo, la validación de las predicciones preelectorales mediante los resultados reales en las elecciones implica que la exactitud es importante y los encuestadores deben evaluar constantemente sus métodos, a la luz de las cambiantes tecnologías de entrevista y otros factores que inciden en las tasas de participación en las encuestas.

\section{LA MECÁNICA GENERAL DE LAS ENCUESTAS PREELECTORALES CONTEMPORÁNEAS}

Para realizar una evaluación de una encuesta preelectoral específica o de encuestas preelectorales en general resulta útil hacerlo desde el enfoque de Total Survey Error (TSE) (Public Opinion Quarterly 2010). 
A pesar de que la casi totalidad de los informes de encuestas preelectorales contienen una declaración sobre el margen de error muestral (MOSE, por su sigla en inglés), esta convención magnifica algunos componentes de error aleatoriamente por lo fácil que resulta calcularlos. Sin embargo, en el proceso de obtención de datos se pueden producir otros tipos de error y de sesgo. Una encuesta implica una serie de pasos realizados de manera secuencial y en algunas o todas las etapas del proceso pueden aparecer errores de diferente índole. El enfoque de TSE divide las fuentes de error en dos grupos: aquéllos relacionados con la medición y aquéllos vinculados con la representación de la población relevante, tal como se aprecia en la figura 1.

Figura 1. UN DIAGRAMA CONCEPTUAL DEL PROCESO DE RECOLECCIÓN DE DATOS USANDO EL ENFOQUE DEL ERROR TOTAL DE ENCUESTA

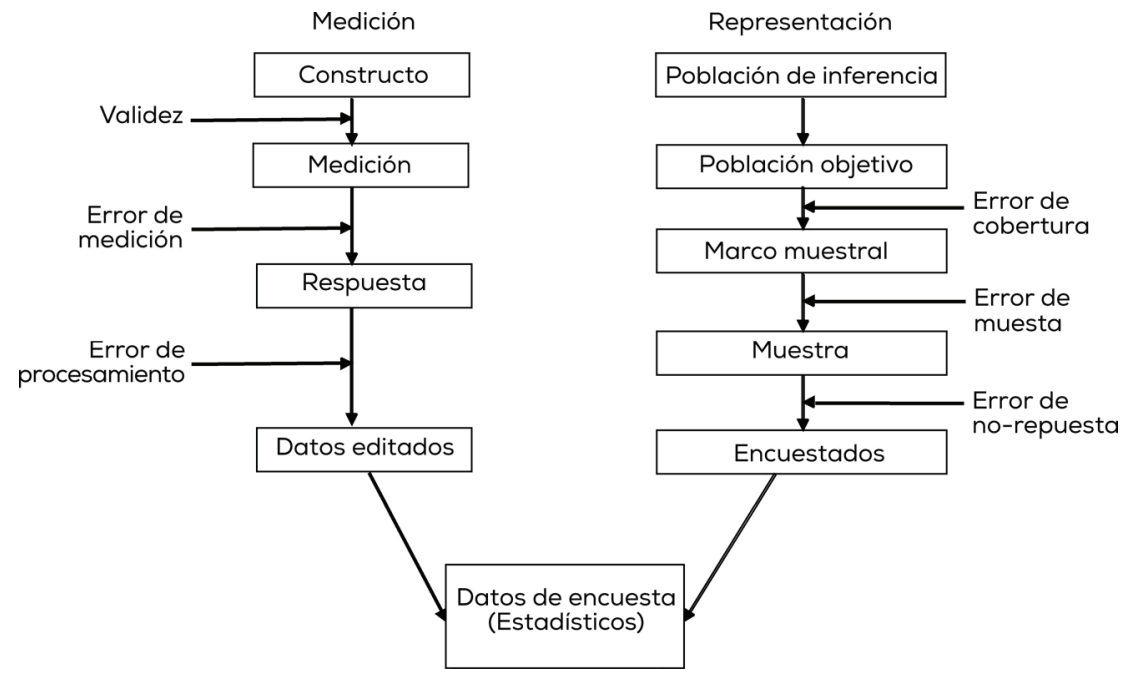

Adaptado de figura 3 en Groves y Lyberg (2006, 856).

En lo que respecta a la medición, el proceso se inicia con la conversión de conceptos o constructos en variables. Para ello se requiere una medición del constructo que permita generar de manera fiable valores que lo reflejen. Esto produce una respuesta de encuesta "bruta", que en algunos casos se combina con otras o es recodificada para producir la medición final que habrá de ser analizada. En el proceso de medición, 
el error puede producirse en la etapa de aplicación donde la validez y/o fiabilidad puede transformarse en un problema debido, por ejemplo, a la formulación de determinadas preguntas o al tipo de categorías de respuesta. La medición también comprende el modo seleccionado para la recopilación de datos, el que puede afectar aspectos como la deseabilidad social en las respuestas. Por ello, en el proceso de medición es preciso pensar en dos conceptos claves en una encuesta preelectoral: intención de votar y preferencia de candidato. La formulación de las preguntas y las opciones de respuesta deben tomar en cuenta las normas de participación (el entrevistado ¿está habilitado para votar en términos de edad y de ciudadanía?, ¿está registrado, si es requerido?) y considerar a todos los candidatos o partidos en la pregunta que mide la preferencia por un candidato (realizar una pregunta abierta sobre opción de voto o una pregunta cerrada con una lista de nombres de candidatos presentada al encuestado; preguntar acerca de todos los candidatos o sólo los principales; permitir que los entrevistados indiquen su preferencia en voz alta o marcando un "voto" de manera privada).

En lo que respecta a la representación, están todos los temas relacionados con qué tan bien los encuestados elegidos representan a la población considerada. Esto comienza con la definición de la población considerada, ya sea de individuos habilitados para votar en un sistema con voto obligatorio o de aquéllos susceptibles de sufragar en un sistema con voto voluntario. La primera tarea de un encuestador es obtener un marco que contenga una lista de votantes habilitados con información de contacto adecuada. Puesto que la mayoría de las entrevistas se realizan por teléfono, esto implica una lista de votantes inscritos con sus números telefónicos. En la práctica, esta lista no existe, por lo que los encuestadores deben construir el marco durante la entrevista. En esa etapa del proceso, puede ocurrir una serie de errores de cobertura, si, por ejemplo, números no inscritos no aparecen en la lista o no son contactados. Otro tema recurrente es reflejar adecuadamente la población de usuarios de telefonía fija y móvil. Después de contactar un hogar y establecer una selección aleatoria de la persona que se va a entrevistar, se debe determinar, a través de varias preguntas, si esa persona es apta para la encuesta. Factores como el momento en que se realiza el trabajo de terreno y su duración, generalmente muy breve en períodos preelectorales, pueden incidir en la tasa de respuesta. Finalmente, el entrevistador de encuestas preelectorales tiene que evaluar la probabilidad 
de que un encuestado sufrague y luego inquirir acerca de sus preferencias de candidato o partido. Ésta es la parte más compleja del proceso de encuesta, pues el concepto de "votante probable" no se materializa efectivamente sino hasta que los ciudadanos toman una decisión y concurren a sufragar el día de las elecciones (Traugott 2015). Los encuestadores preelectorales deben determinar las propensiones individuales a votar, las que son más fuertes o claras a medida que se acerca al día de las elecciones. En los sistemas políticos en que las encuestas deben interrumpirse una o dos semanas antes del sufragio esto es más difícil de lograr que cuando los sondeos están autorizados hasta el momento de emitir el voto. Por todas esas razones, los temas relacionados con los modelos de votantes probables son tratados en otro artículo (Traugott 2015).

Más allá de todas estas consideraciones políticas y administrativas, las reglas y las normativas electorales están cambiando de manera constante. Se modifican los procedimientos de inscripción y de sufragio, así como los utilizados para emitir el voto. En un número creciente de democracias, el proceso electoral se desarrolla durante varios días y en algunos casos, durante varias semanas, a través de un voto no presencial o de diversos procedimientos de voto anticipado. Al mismo tiempo, los encuestadores deben lidiar con temas como la aparición de nuevas tecnologías para entrevistar, la necesidad de reducir los costos relacionados con la recopilación de datos y estrategias comunicacionales, publicitarias y de movilización cada vez más sofisticadas por parte de los candidatos y sus partidos. De cara a esto, resulta sorprendente que los encuestadores preelectorales hayan seguido mejorando sus predicciones en las elecciones nacionales en las últimas dos décadas y a lo largo de varios países. Sin embargo, sus resultados en elecciones locales o subnacionales, ya sea de alcaldes, gobernadores o en elecciones estatales y legislativas locales, son más deficientes. El principal problema para estimar los niveles de participación cuando estas elecciones de menor convocatoria se celebran en diferentes momentos se debe a que suele haber una correlación entre participación y atomización del apoyo a los candidatos.

Otros problemas metodológicos pueden surgir cuando las encuestas dejan de ser presenciales y se recurre al teléfono o a internet. Los diseños de las muestras y las no respuestas relativas pueden tornarse 
complejos, al igual que la determinación de la proporción relativa de teléfonos celulares y teléfonos fijos en la muestra. El problema más común es una estimación de votante probable que se traduzca en un grupo hipotético de sufragantes demasiado grande o pequeño, en comparación con el número de personas que concurren a las urnas o con características demográficas diferentes a las del electorado real, lo que trae consecuencias partidistas. En la siguiente sección se discuten algunos de estos temas.

\section{EJEMPLOS DE TEMAS Y PROBLEMAS DE LAS ENCUESTAS PREELECTORALES ALREDEDOR DEL MUNDO}

En esta sección analizaremos cinco ejemplos de problemas que han debido enfrentar encuestadores en elecciones recientes y que se tradujeron en errores de estimación significativos. Estos casos ilustran la gama de dificultades que pueden relacionarse con problemas metodológicos. La muestra no pretende ser exhaustiva; más bien, los ejemplos escogidos muestran la variedad de posibilidades y de circunstancias que enfrentan los encuestadores. Vienen a ilustrar dos importantes consideraciones: la primera es que determinar las causas de los errores de estimación puede resultar arduo, pues su análisis, generalmente, se realiza después de que estos se cometieron, por lo tanto, la investigación en la mayoría de las instancias se efectúa ex post facto, lo que dificulta la demostración de relaciones causales. La segunda consideración es la falta de transparencia en la difusión de las metodologías empleadas por los encuestadores preelectorales, especialmente en el caso de las empresas, que se niegan a hacer público lo que consideran como metodologías de su propiedad.

A pesar de que esto aún no es cierto en el caso de Chile, la amplia mayoría de los encuestadores preelectorales en el mundo realizan sus entrevistas por teléfono. El escenario tecnológico actual con que muchos encuestadores preelectorales deben lidiar es cómo dar cuenta de las diferencias en los patrones de uso de telefonía fija y móvil entre distintos grupos sociales. En los Estados Unidos, la adopción de teléfonos celulares y el auge de hogares que sólo utilizan telefonía celular han sido fenómenos de rápido crecimiento. Un problema que enfrentan los encuestadores es decidir qué porcentaje de hogares con telefonía celular 
y con telefonía fija incorporar en sus muestras. No se trata únicamente de incluir una proporción adecuada de ambos dispositivos; existen también complicaciones legales y de procedimientos. Es ilegal en los Estados Unidos llamar a un teléfono celular desde un computador, técnica estándar en el caso de los teléfonos fijos. Asimismo, establecer un vínculo entre las llamadas a un aparato celular y la ubicación geográfica es más complejo, porque algunos teléfonos son adquiridos por las empresas en el lugar donde se localiza la casa matriz y su número registra dicho código de área cuando es posible que el usuario viva en otro lugar del país. Debido a que la tasa de respuesta para las llamadas a teléfonos celulares es más baja y puede requerir más llamadas sucesivas para contactar a un potencial entrevistado, las entrevistas realizadas en un teléfono celular son más costosas que las efectuadas en un teléfono fijo. Recientemente, se estimó que era dos veces más caro realizar una entrevista a través de un teléfono celular en los Estados Unidos que a través de un teléfono fijo (AAPOR 2010), a pesar de que hay indicios que sugieren que esta diferencia ha disminuido en parte y ahora pueden elaborarse modelos para determinados tipos de encuesta con la proporción exacta de teléfonos celulares y fijos, en un diseño de doble marco muestral (Levine y Harter por publicarse).

Igualmente importante es quién es agregado y omitido en una muestra dependiendo de si se incluyeron o no los números de teléfonos celulares al momento de diseñarla (Keeter 2006). Tomando nuevamente como ejemplo a los Estados Unidos, la mejor información disponible sobre uso de telefonía celular proviene de un estudio del Centro Nacional para Estadísticas de Salud, que entrega un informe bianual sobre propiedad y patrones de uso desde 2003. En su último informe, Blumberg y Luke (2014) indican que el 41 por ciento de los hogares estadounidenses sólo utilizaban telefonía celular — en otras palabras, no tenían red fija-, una tendencia que ha venido creciendo de manera sostenida durante la última década. Más importantes son las diferencias demográficas: dos tercios (65,7 por ciento) de las personas entre 25 y 29 años viven en hogares con sólo telefonía celular; asimismo, más de la mitad (53,1 por ciento) de la población hispana y el 61,7 por ciento de los adultos que arriendan la vivienda en que habitan sólo utilizan teléfono celular, comparado con el 28,5 por ciento de los que viven en su propia casa o en la de un familiar. Naturalmente, estas diferencias sólo son relevantes si estas características demográficas se relacionan con otras 
variables políticamente significativas; y en muchos casos eso es así. Por ejemplo, los adultos jóvenes en los Estados Unidos tienden más a identificarse con el Partido Demócrata, tal como los hispanos. Su omisión en encuestas telefónicas de carácter político producirán una subestimación en el apoyo a los candidatos demócratas o a Barack Obama específicamente, o ciertas preferencias en determinados temas políticos, como la inmigración. En otros países, la relación entre edad o raza y etnicidad y partidos políticos podría naturalmente ser diferente.

Sometidos a una presión constante de reducir costos, los encuestadores optarán cada vez más por recopilar datos a través de internet. Existen importantes temas de cobertura, asociados con la introducción de internet en los hogares, que plantean interrogantes en términos de sesgo de selección de la muestra (Bethlehem 2010); así como preocupaciones sobre repetidos muestreos aplicados sobre el mismo panel de encuestados potenciales, lo que, además de participar en múltiples encuestas para obtener una compensación, podría derivar en que los encuestados se conviertan en profesionales de responder encuestas (Toepoel et al. 2008). Estos y otros temas asociados con el uso de diseños no probabilísticos (AAPOR 2013) deberán ser analizados por los investigadores a medida que se vuelven más generalizados.

\section{Problemas de muestreo: Encuesta preelectoral en Corea del Sur en 2009}

En 2010, Corea del Sur realizó elecciones locales de alcaldes y gobernadores. Las encuestas preelectorales erraron seriamente en sus predicciones en lo que respecta a los partidos (con diferencias que oscilaban entre los 3 y los 20 puntos porcentuales) y a los ganadores en varias zonas geográficas. Las encuestas preelectorales conferían un apoyo significativo y estable para el Gran Partido Nacional (Grand National Party, GNP), subestimando el apoyo al Partido Democrático Unido (United Democratic Party, DP) en las mismas zonas. En el gráfico 1 se presenta un ejemplo de este problema de estimación, ilustrado con series temporales de los resultados de las encuestas para la elección de alcalde en Incheon en el año 2010. A pesar de que las encuestas indicaban una ventaja de ocho a doce puntos porcentuales para el Gran Partido Nacional, el candidato del Partido Democrático Unido se impuso por ocho puntos porcentuales. 
Los análisis postelectorales aludieron a un efecto de "espiral de silencio" - según el cual los ciudadanos se inclinaban por el partido que iba a la zaga pero eran reacios a declararlo públicamente- y a cambios de último minuto en la preferencia de voto; sin embargo, ninguna evidencia empírica respaldaba esas teorías. Estas explicaciones se ajustan a la observación de Durand (2011) respecto de las razones que suelen dar los encuestadores para justificar sus errores de estimación.

Gráfico 1. SERIES TEMPORALES DE RESULTADOS DE ENCUESTAS ANTES DE LA ELECCIÓN DE ALCALDE DE 2010 EN INCHEON

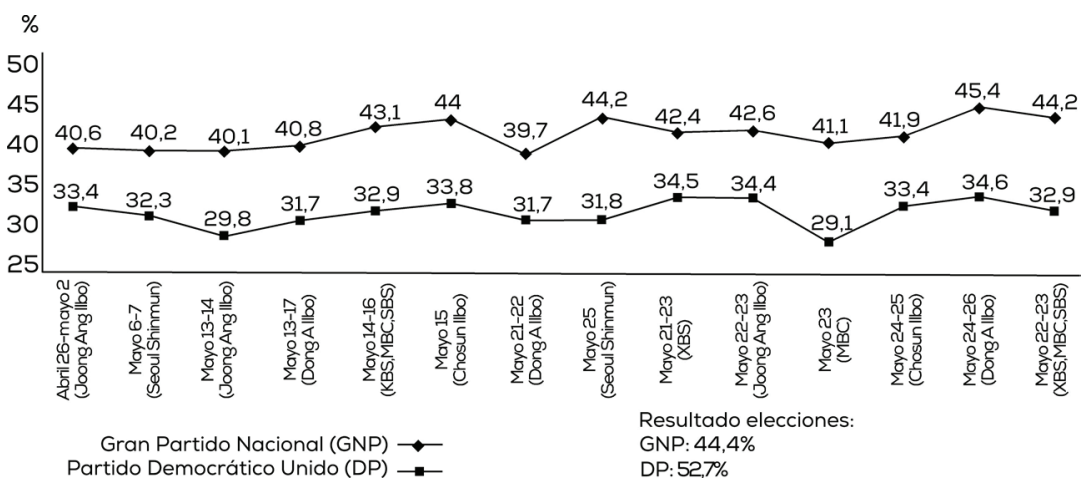

¿Cómo explicar entonces estos errores? La metodología estándar utilizada por los encuestadores en Corea incluye muestras obtenidas de teléfonos fijos registrados con muestreo por cuotas de individuos al interior de los hogares contactados. Esto plantea una serie de problemas, como la omisión de individuos que operan con teléfonos móviles y la exclusión de teléfonos fijos no inscritos, la ausencia de métodos probabilísticos para la selección de individuos dentro de los hogares y las consecuencias de ambas innovaciones en la ponderación de los datos resultantes. Más aún, el muestreo por cuotas sólo puede aplicarse para características conocidas y observables como el género, pero es claramente inadecuado cuando características inobservables como el apoyo al partido gobernante o la adhesión política son importantes. Kim et al. (2011) realizaron un estudio postelectoral con varias innovaciones metodológicas para ver cómo podrían encontrar solución a estos problemas.

La primera innovación fue el uso de una muestra de doble marco de discado de número aleatorio (RDD, por su nombre en inglés: ran- 
dom digit dialed), en la cual los números de teléfonos fijos y teléfonos móviles se generaban de manera aleatoria. Es sabido que un creciente segmento de la población que opera con teléfonos celulares es más joven, más móvil y corresponde a una combinación de individuos con niveles altos y bajos de educación. Estas situaciones suelen traducirse en diferencias respecto de la identificación con partidos políticos dentro de ese grupo comparado con el resto de la población, lo que a su vez puede dificultar la estimación de resultados electorales (Pew 2010, 2013). Un diseño de doble marco puede también dar cuenta de los problemas de falta de cobertura relacionados con hogares con números fijos no registrados y con aquellos que utilizan telefonía móvil de manera principal o exclusiva. ${ }^{1}$ El diseño de encuesta incorporaba también una selección aleatoria de individuos dentro de los hogares, mientras que el cuestionario recababa información sobre las diferentes formas en que el entrevistado seleccionado podría haber sido contactado por teléfono. Finalmente, se utilizó un sistema optimizado de ponderación para incorporar esta información sobre selección frente a los métodos estándares empleados por los encuestadores comerciales.

Basándose en este enfoque postelectoral, en el que los encuestados revelaron su intención y comportamiento de voto, los autores identificaron varias características de la composición de la muestra y mejoraron la estimación. Por ejemplo, había claras diferencias en la distribución de edad de la nueva muestra coreana - fenómeno que se repetiría en la mayoría de los países - cuando se agregaba la muestra de telefonía celular RDD, como se muestra en el cuadro 1. En la muestra de telefonía celular, la cantidad de encuestados de entre 19 y 29 años era el doble que en la muestra de telefonía fija, un subconjunto de la muestra RDD de telefonía fija. Esto hizo que la muestra de doble marco de ciudadanos y de votantes fuera más representativa de ambas poblaciones.

La muestra RDD de doble marco incluía 14 por ciento de personas en el grupo etario 19-29, comparado con el 18 por ciento del censo de Corea de 2010 y el 15 por ciento de los sufragantes, según un estudio postelectoral realizado por la Comisión Nacional Electoral de Corea (KNEC, por su nombre en inglés). Las personas jóvenes tienden a su-

${ }^{1}$ Los diseños de doble marco no están exentos de problemas: por ejemplo, encuestados que tienen a la vez teléfonos fijos y celulares, y los efectos sobre la probabilidad de la selección (Kennedy 2007). 
fragar menos que las mayores. Naturalmente, estas diferencias demográficas en las muestras no tendrían ninguna incidencia si no estuvieran asociadas con patrones diferenciados de apoyo a los partidos por edad o por uso de teléfono celular. Eso terminó también siendo el caso, puesto que había una fuerte correlación entre la magnitud de la subestimación del apoyo al Partido Democrático Unido y la proporción de usuarios exclusivamente de telefonía celular en esas zonas. El uso de un marco y método muestral apropiados para la selección de encuestados dentro de los hogares, entonces, incide en las características de la muestra resultante, lo que a su vez afecta las estimaciones de apoyo a los diferentes partidos políticos.

Cuadro 1. CARACTERÍSTICAS DE LA MUESTRA PONDERADA POR EDAD DE LOS VOTANTES DECLARADOS EN COREA

\begin{tabular}{lcccccc}
\hline Edad & $\begin{array}{c}\text { Telefoní fija } \\
\text { registrados }\end{array}$ & $\begin{array}{c}\text { Telefoní fija } \\
\text { RDD }\end{array}$ & $\begin{array}{c}\text { Cel. } \\
\text { RDD }\end{array}$ & $\begin{array}{c}\text { Doble } \\
\text { RDD }\end{array}$ & $\begin{array}{c}\text { Censo } \\
2010\end{array}$ & KNEC \\
\hline $19-29$ & $7 \%$ & $8 \%$ & $17 \%$ & $14 \%$ & $18 \%$ & $15 \%$ \\
$30-39$ & 6 & 14 & 21 & 20 & 21 & 18 \\
$40-49$ & 23 & 29 & 25 & 26 & 22 & 22 \\
$50-59$ & 24 & 19 & 17 & 18 & 18 & 20 \\
60 o más & 39 & 30 & 21 & 23 & 21 & 25 \\
\hline Total & $100 \%$ & $100 \%$ & $100 \%$ & $100 \%$ & $100 \%$ & $100 \%$ \\
\hline N & 335 & 624 & 400 & 1.024 & & \\
\hline
\end{tabular}

KNEC: \% de sufragantes efectivos según Comisión Electoral de Corea.

Nota: En los casos en que las columnas no sumen $100 \%$ se debe a las modificaciones causadas por la aproximación de decimales.

Fuente: Datos adaptados de Kim et al. (2011).

\section{Administración de encuestas y efectos contextuales:} Encuestas preelectorales en México

Moreno, en forma individual y en colaboración (2009, 2010 y 2012), ha estudiado las causas de los errores de estimación en recientes elecciones subnacionales y regionales en México. Ha sido un período en el que las adhesiones a los principales partidos políticos de México han ido cambiando, tanto a nivel nacional como local, en términos de apoyo a cada una de las colectividades y en términos de coaliciones po- 
líticas. Esto comenzó con la caída de apoyo al PRI, a la que siguió una alianza inédita entre partidos de izquierda y de ultraderecha, específicamente el PRD y el PAN. En México, existe el Instituto Federal Electoral (IFE), encargado de compilar los datos de las elecciones y supervisar el cumplimiento de las regulaciones sobre campañas electorales. En Cocoyoc, en el año 2010, éste organizó una reunión de encuestadores, investigadores académicos de encuestas y participantes en campañas políticas, para debatir sobre los problemas relacionados con las encuestas de las elecciones de 2009. Se planteó, en términos generales, la idea de un proyecto de investigación colaborativo que pudiera realizarse a través de experimentos basados en hipótesis en una próxima elección; sin embargo, el espíritu de cooperación se esfumó poco después de que concluyera la reunión y nunca se realizaron estudios empíricos.

Moreno, Aguilar y Romero (2012), por su parte, se valieron de algunos datos de las encuestas que el primero de estos autores había realizado para el periódico Reforma para investigar posibles relaciones entre factores metodológicos y contextuales que pudieran asociarse con problemas de medición y errores de estimación. Analizaron 16 hipótesis que podían ser evaluadas en los datos recabados en el Estado de México, entre ellas, el impacto de factores como el diseño muestral, el lugar de la pregunta en el cuestionario, los procedimientos de entrevista y efectos contextuales, como un "entorno inseguro o amenazante" relacionado con la violencia o el crimen en la zona donde se estaba realizando la entrevista. $^{2}$

Los investigadores mexicanos analizaron la eventualidad de efectos de "espiral de silencio" y cambios de último minuto en la intención de voto. Las variables dependientes eran el error de estimación absoluto total y el error absoluto en la estimación de apoyo para cada uno de los principales partidos; la unidad de análisis era el área muestral en el que se habían realizado los grupos de entrevistas. Estos son los datos observados en las encuestas preelectorales y no el resultado de un nuevo muestreo aleatorio.

2 Este es un problema serio en México. Dos entrevistadores de dos empresas de sondeos que estaban realizando entrevistas antes de las elecciones de 2011 en Michoacán, México, fueron secuestrados y mantenidos en cautiverio durante tres días antes de ser liberados. Para más información, consúltese: http://wapor.org/wpcontent/uploads/2011/08/Mexico-2011.pdf/ 
Los autores observaron que sustituir encuestados en la muestra debido a no respuestas no tenía efecto en el error absoluto total, pero la inclusión de la variable de proporción de entrevistados provenientes de zonas rurales sí reducía el error. Las mujeres entrevistadoras así como aquellos debidamente supervisados también reducían el error; sin embargo, la edad o la experiencia del entrevistador no tenían mayor incidencia. Al mismo tiempo, el lugar de la pregunta sobre opción de voto en el cuestionario no tenía un efecto significativo en el error de estimación, al igual que el entorno en el que se realizaron las entrevistas. Sin embargo, el lugar de la pregunta en el cuestionario se relacionaba con el género del entrevistado, en términos de que los varones eran más proclives a manifestar su apoyo por el candidato del PAN cuando ésta se formulaba en la mitad de la encuesta y la no respuesta para la pregunta de opción de voto era significativamente más baja para las mujeres cuando la pregunta surgía al inicio de la entrevista.

Generalmente, la proporción de encuestados que tenía una preferencia o un punto de vista minoritario en su zona local no implicaba un efecto sobre el error absoluto total, pero cuando el encuestador señalaba que el entrevistado parecía sentirse presionado durante la entrevista, aumentaba el error absoluto promedio. La cantidad de personas indecisas en la zona, un indicador del potencial para cambios de opinión de última hora, no tenía incidencia. Cuando se analizaron los datos de errores de estimación para los principales partidos, se registraron algunas diferencias en la magnitud de los efectos para determinadas variables independientes. A pesar de que la edad del entrevistador no tenía un efecto global sobre el error absoluto total, reducía los errores en la estimación del apoyo hacia el PRI, pero los aumentaba en las estimaciones para el PAN. Sería interesante analizar también la diferencia relativa de edad entre el entrevistador y el entrevistado.

A pesar de que este análisis se basó en datos de una elección en un solo Estado mexicano, ilustra la posibilidad de descubrir relaciones entre factores que podrían relacionarse con errores absolutos totales y con errores en la estimación del apoyo hacia partidos individuales. Más allá de los factores específicos considerados, relacionados con el manejo de las encuestas, los autores sugieren que la estimación del apoyo a nuevos candidatos también puede ser un tema a considerar, basándose en el estudio de Traugott y Wlezien (2009) en las primarias de las elecciones en 
los Estados Unidos. Concluyen manifestando la necesidad de replicar sus resultados analizando otras elecciones locales en México y en otros países.

\section{Muestreo y modelos de votante probable: Encuestas preelectorales en los Estados Unidos en 2012}

En los Estados Unidos se utilizan hoy algunas de las más avanzadas técnicas de sondeos preelectorales y la exactitud de los resultados en las encuestas de las elecciones presidenciales ha sido creciente en los últimos 20 años. Los patrones generales de las estimaciones de los sondeos en las primarias (Traugott y Wlezien 2009) y en las elecciones generales (Erikson y Wlezien 2012) han sido estudiados en profundidad y se han observado elementos recurrentes. Por ejemplo, el nivel estimado de adhesión al candidato ganador ha sido sobreestimado de manera consistente en ambos tipos de elecciones, mientras que el apoyo a los candidatos que desafían al que lidera en las preferencias muchas veces ha sido subestimado.

En las elecciones generales de 2012, cuando Barack Obama ganó la reelección derrotando a Mitt Romney, ocurrieron dos situaciones anómalas interesantes que no fueron anticipadas por los modelos de comportamiento electoral. La primera fue que, más que sobreestimar el apoyo a Obama, a pesar de que ganó de manera relativamente holgada por casi cuatro puntos porcentuales, la mayoría de los sondeos preelectorales subestimaron su porcentaje del voto popular. Este fenómeno se ilustra en el cuadro 2, que muestra los errores de estimación por tamaño y signo para 25 empresas de encuestas de opinión. Obsérvese que 24 empresas subestimaron el apoyo a Obama y 23 su margen de victoria. Pese a que las diferencias en los márgenes estaban dentro del margen de error muestral, lo que perturbó a los críticos y sorprendió a los encuestadores fue la consistencia en su dirección. La medida de exactitud, "A", tiene un valor equivalente a cero cuando el log de la estimación de la proporción de apoyo entre el candidato republicano y el demócrata en la encuesta es igual al resultado de las elecciones (Martin et al. 2005). Su valor es positivo cuando la encuesta favorece al candidato republicano en relación con el resultado de la elección y es negativo cuando la estimación favorece al candidato demócrata. 
Cuadro 2. EXACTITUD Y SESGO EN LAS ENCUESTAS PREELECTORALES FINALES EN LA ELECCIÓN PRESIDENCIAL DE 2012 EN LOS ESTADOS UNIDOS

\begin{tabular}{|c|c|c|c|c|c|c|}
\hline EMPRESA & $\begin{array}{l}\text { Fechas de } \\
\text { terreno }\end{array}$ & $\begin{array}{c}\% \\
\text { Romney }\end{array}$ & $\begin{array}{c}\% \\
\text { Obama }\end{array}$ & Diferencia & $\begin{array}{l}\text { Tamaño } \\
\text { de la } \\
\text { muestra }\end{array}$ & $\begin{array}{l}\text { Exactitud } \\
\text { predictiva } \\
\text { (A) }\end{array}$ \\
\hline $\begin{array}{l}\text { Resultados de las } \\
\text { elecciones }\end{array}$ & & 47,2 & 51,1 & 3,9 & & \\
\hline $\begin{array}{l}\text { Democracy Corps } \\
\text { (D) }\end{array}$ & $1 / 11-4 / 11$ & 45 & 49 & 4,0 & 1080 & $-0,008$ \\
\hline Pew Research & $31 / 10-3 / 11$ & 45 & 48 & 3,0 & 2709 & 0,013 \\
\hline $\begin{array}{l}\text { ABC News/Wash- } \\
\text { ington Post }\end{array}$ & $11 / 11-4 / 11$ & 47 & 50 & 3,0 & 2345 & 0,016 \\
\hline Angus-Reid & $1 / 11-3 / 11$ & 48 & 51 & 3,0 & 1019 & 0,017 \\
\hline National Journal & $25 / 10-28 / 10$ & 45 & 50 & 5,0 & 713 & $-0,028$ \\
\hline Ipsos/Reuters & $1 / 11-5 / 11$ & 46 & 48 & 2,0 & 4725 & 0,035 \\
\hline YouGov & $31 / 10-3 / 11$ & 47 & 49 & 2,0 & 36472 & 0,036 \\
\hline $\operatorname{PPP}(D)$ & $2 / 11-4 / 11$ & 48 & 50 & 2,0 & 1200 & 0,037 \\
\hline Daily Kos/SEIU/PPP & $1 / 11-4 / 11$ & 48 & 50 & 2,0 & 1300 & 0,037 \\
\hline Purple Strategies & $31 / 10-1 / 11$ & 46 & 47 & 1,0 & 1000 & 0,056 \\
\hline $\begin{array}{l}\text { NBC News/Wall } \\
\text { Street Journal }\end{array}$ & $1 / 11-3 / 11$ & 47 & 48 & 1,0 & 1475 & 0,056 \\
\hline $\begin{array}{l}\text { CBS News/New York } \\
\text { Times }\end{array}$ & $25 / 10-28 / 10$ & 47 & 48 & 1,0 & 563 & 0,056 \\
\hline UPI/CVOTER & $3 / 11-5 / 11$ & 48 & 49 & 1,0 & 3000 & 0,057 \\
\hline IBD/TIPP & $3 / 11-5 / 11$ & 49 & 50 & 1,0 & 712 & 0,057 \\
\hline CNN/ORC & $2 / 11-4 / 11$ & 49 & 49 & 0,0 & 693 & 0,077 \\
\hline $\begin{array}{l}\text { Monmouth/ } \\
\text { SurveyUSA }\end{array}$ & $1 / 11-4 / 11$ & 48 & 48 & 0,0 & 1417 & 0,077 \\
\hline $\begin{array}{l}\text { Politico/GWU/ } \\
\text { Battleground }\end{array}$ & $4 / 11-5 / 11$ & 47 & 47 & 0,0 & 1000 & 0,077 \\
\hline $\begin{array}{l}\text { Washington Times/ } \\
\text { JZ Analytics }\end{array}$ & $29 / 10-31 / 10$ & 49 & 49 & 0,0 & 800 & 0,077 \\
\hline $\begin{array}{l}\text { American Research } \\
\text { Group }\end{array}$ & $2 / 11-4 / 11$ & 49 & 49 & 0,0 & 1200 & 0,077 \\
\hline Gravis Marketing & $11 / 3-11 / 5$ & 48 & 48 & 0,0 & 872 & 0,077 \\
\hline Fox News & $28 / 10-30 / 10$ & 46 & 46 & 0,0 & 1128 & 0,077 \\
\hline Rasmussen & $3 / 11-5 / 11$ & 49 & 48 & $-1,0$ & 1500 & 0,098 \\
\hline Gallup & $1 / 11-4 / 11$ & 49 & 48 & $-1,0$ & 2700 & 0,098 \\
\hline NPR & $23 / 10-25 / 10$ & 48 & 47 & $-1,0$ & 1000 & 0,098 \\
\hline AP/GfK & $19 / 10-23 / 10$ & 47 & 45 & $-2,0$ & 839 & 0,121 \\
\hline
\end{tabular}

Fuente: Panagopoulos y Farrer (2014), complementada por datos de RealClearPolitics, disponibles en http://www.realclearpolitics.com/epolls/2012/president/us/general election_romney_vs_obama-1171.html\#polls/ 
La explicación generalmente aceptada es que la campaña de Obama movilizó mejor a sus adherentes; por ejemplo, 2012 fue la primera elección en que la participación del electorado afroamericano superó a la de la población blanca (Yen 2013). Esto también implicaría que los algoritmos estándares de ponderación para la muestra de votante probable, basados en el comportamiento proporcional de voto en elecciones previas, probablemente también estaban errados. Más aún, cuatro empresas de sondeos (Gallup, Rasmussen Reports, NPR y AP/GfK) produjeron estimaciones que sugerían que Romney ganaría por un estrecho margen. Cuando Obama ganó por 3,9 puntos porcentuales, estos resultados combinados plantearon serias interrogantes sobre los métodos de sondeo utilizados y sobre la necesidad de cambiarlos.

Partiendo por el tema general de la subestimación del apoyo a Obama, las campañas electorales en los Estados Unidos han ido cambiando en el último tiempo en varios aspectos. Uno de ellos son las sumas de dinero que gastan, a medida que los candidatos de los partidos más importantes exceden el financiamiento federal, ya que pueden recaudar más fondos por su propia cuenta a través de técnicas cada vez más sofisticadas basadas en la web. Por otra parte, resoluciones recientes de la Corte Suprema han dado luz verde para que grupos independientes puedan recaudar y gastar más fondos para campañas presidenciales. En la campaña de 2012, Barack Obama y sus comités de acción política (PAC, por su nombre en inglés) superaron en recaudación y gasto a Mitt Romney y sus PAC, cuando cada bando terminó desembolsando más de mil millones de dólares. Lo más importante es que el gasto no estaba distribuido en todo el territorio estadounidense de acuerdo con la distribución de la población de votantes. Las campañas destinaron una parte considerable de sus fondos a los Estados claves, donde la competencia era más estrecha y las encuestas públicas y privadas indicaban que los resultados serían decisivos. Hay motivos para pensar que estos patrones de gasto incidieron en la subestimación del apoyo a Obama. Prácticamente todos los gastos publicitarios y llamados a votar se concentraron en sólo diez Estados; su campaña destinó más fondos a Florida que a los 40 Estados restantes (Pillsbury y Johannsen 2013). La participación en la elección presidencial de 2012 fue levemente inferior que la de 2008 a nivel nacional, pero aumentó en estos diez Estados, nueve de los cuales se inclinaron por Obama. Las encuestas preelecto- 
rales no han estratificado sus diseños muestrales por Estado clave o por región, y estos Estados parecen haber sido subestimados en la mayoría de las encuestas en términos de su contribución al resultado nacional. Considerando el éxito que Obama obtuvo en ellos, se podría explicar la subestimación de su apoyo global en todas las encuestas nacionales.

Gallup realizó una evaluación de su encuesta preelectoral en dos partes. En junio de 2013 elaboró un informe sobre una serie de análisis que efectuó sobre su metodología de sondeos preelectorales (Gallup 2013). Se identificaron varios factores que incidieron o pudieron incidir en sus errores de estimación, entre ellos su modelo de votante probable. Hallaron que el porcentaje de entrevistas a través de teléfonos celulares en sus muestras era muy bajo, la codificación de la raza o etnicidad podía optimizarse y que el control geográfico de entrevistas entre regiones podía mejorarse a través de una gestión de encuestas para reflejar mejor los porcentajes adecuados en los Estados Unidos. Todos estos cambios se realizaron en los procedimientos. Posteriormente, se llevó a cabo una serie de experimentos en las elecciones estatales de 2013 de Nueva Jersey y Virginia, poniendo el foco en procedimientos alternativos para capturar al votante probable y en aspectos metodológicos, como la formulación de las preguntas. Los resultados de estos experimentos, presentados en la conferencia de 2014 de la Asociación Estadounidense para la Investigación sobre Opinión Pública, no fueron concluyentes con respecto a modelos alternativos de votante probable (Astudillo et al. 2014), pero, en cambio, demostraron que sí se podía mejorar la formulación de las preguntas (McClain y Spiegelman 2014).

\section{Modelos de participación y de votante probable: Encuestas preelectorales en los Estados Unidos en 2014}

El problema del sesgo también surgió en las evaluaciones de desempeño de las encuestas preelectorales de 2014. En las elecciones legislativas, la participación es usualmente más baja que en las presidenciales; en los comicios de 2014, la participación fue la más baja desde 1942 (DelReal 2014). Puesto que las elecciones para gobernadores y senadores son, en estas votaciones, las más candentes, con candidatos visibles que gastan sumas considerables de dinero, la gran mayoría de las encuestas en este período se realizan a nivel estatal y no nacional. 
Como ya se indicó en la experiencia reciente de México, las encuestas subnacionales suelen arrojar una mayor variabilidad que las nacionales, pero el problema del sesgo no ha sido estudiado en profundidad.

Silver (2014) comentó sobre la variabilidad en el sesgo de las encuestas en años de elecciones legislativas, desde 1990 hasta 2014. Los datos en el gráfico 2 ilustran una serie de puntos. En primer lugar, hay una mayor variabilidad en las encuestas de elecciones legislativas que en las de elecciones presidenciales, en otras palabras, el sesgo promedio es mayor. Segundo, el sesgo en las encuestas de años no presidenciales no favorece a un partido con respecto a otro. En 1998, benefició claramente a los republicanos (en otras palabras, subestimó a los demócratas) y en 2014, a los demócratas. Cabe destacar que el sesgo era relativamente amplio en las últimas dos elecciones (tanto presidencial como legislativa) comparado con otras anteriores. La participación fue relativamente alta en la elección presidencial de 2012, pero históricamente baja en la elección legislativa de 2014.

\section{Gráfico 2. SESGO PARTIDISTA EN LAS ENCUESTAS SENATORIALES DE EE.UU.}

Sesgo estadistico promedio en las encuestas realizadas en los 21 días finales de campaña electoral, 1990-2014

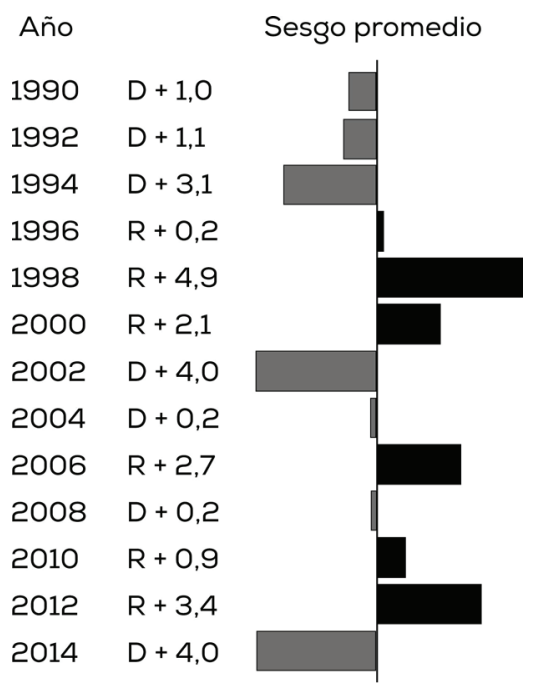

Fuente: Silver (2014), disponible en http://fivethirtyeight.com/features/the-polls-wereskewed-toward-democrats/ 
Un tema a considerar es cómo interpretar el significado del sesgo en las encuestas senatoriales. ¿Se trata de una coincidencia única o del inicio de una nueva tendencia? A nivel estatal, algunas de las diferencias más marcadas entre las estimaciones de las encuestas y la división real del voto se produjeron en las que parecían ser las competencias más estrechas. Si esa variabilidad se transforma en la nueva norma, ¿qué orientación nos entrega respecto de cómo deberían realizarse o ajustarse las encuestas en el ciclo electoral de 2016? Este es un nuevo tema de discusión entre los encuestadores de opinión estadounidenses (Rivers 2014; Wang 2014).

\section{Subestimación del apoyo a los partidos regionales en Canadá}

Durand (2011) ha estudiado los errores en las encuestas preelectorales en Canadá desde el año 2000, con un énfasis particular en los problemas surgidos en las elecciones locales de Ontario y Quebec. Ella señala que las encuestas subnacionales suelen contar con muestras más pequeñas porque los medios locales no tienen los mismos presupuestos para cubrir estas elecciones frente a las nacionales. También plantea preguntas sobre el comportamiento estratégico electoral de los votantes en distritos donde sólo hay un escaño en disputa y su decisión puede ser influida por los datos de encuestas respecto de quién va primero y quién va segundo.

Una peculiaridad del sistema canadiense es una subestimación bastante consistente del apoyo al Partido Conservador y al Partido Quebequés. Este problema puede deberse a muchos factores. Los problemas de ponderación pueden surgir cuando los encuestadores no dan cuenta adecuadamente de la proporción de encuestados en la muestra que tienen otras lenguas maternas. En las muestras nacionales, además, algunos encuestadores no ponderan debidamente la contribución relativa de entrevistados provenientes de provincias específicas en relación con las contribuciones de los votantes de los mismos lugares a los totales de votos finales. Otro tema es el uso reciente de encuestas realizadas con sistemas de respuesta interactiva de voz (IVR, por su nombre en inglés), generalmente considerada como una metodología que permite ahorrar costos, y el descubrimiento de que algunas empresas de sondeos sólo realizaron llamadas con un sistema de entrevistas computarizadas grabadas en inglés, cuando un porcentaje significativo de la población habla francés como idioma principal y como motivo de orgullo cívico. 
Algunas empresas de sondeo de opinión, especialmente en Quebec, están recurriendo a muestras obtenidas de paneles de encuestados de internet dispuestos a participar. Los estudios han demostrado que los paneles con participantes que optan libremente por intervenir suelen producir muestras que son de personas más jóvenes e ideológicamente más moderadas o liberales que las muestras probabilísticas en relación con la población total (Traugott 2012). Muchas empresas de encuestas ajustan este factor a través de modelaciones o ponderaciones, pero no divulgan los detalles metodológicos de cómo se calculan estas ponderaciones. Esto puede resultar más problemático en ciertos tipos de elecciones que en otros, pero se trata de un área en la cual se requiere más transparencia e investigación.

\section{DISCUSIÓN}

Las encuestas preelectorales realizadas en distintas democracias con diversos sistemas de votación, diseños de muestra, procedimientos en terreno y empleando diferentes modelos de votante probable a veces enfrentan dificultades para producir estimaciones exactas y no sesgadas. Una reseña de cinco circunstancias distintas en cuatro países ilustra la gama de problemas que han debido enfrentar recientemente las empresas de sondeo de opinión. A pesar de que las encuestas preelectorales se vienen realizando en Chile hace 50 años (Navia 2003), la exactitud de sus predicciones ha sido desigual. En los primeros años, muchas encuestas sólo realizaron entrevistas en Santiago, Valparaíso y Concepción; la opinión de los ciudadanos que vivían en las zonas rurales del país fue ignorada. Después de una década de ausencia en los años setenta, las encuestas políticas volvieron a aparecer a fines de los años ochenta, antes del plebiscito. Muchas empresas de opinión se alinearon con partidos y candidatos específicos o tomaron posición contra ellos, y los temas éticos y conflictos de intereses se volvieron usuales, especialmente cuando ocurrían errores de estimación. Eso generó un creciente escepticismo ante las encuestas. Algunas empresas de opinión abandonaron las entrevistas presenciales y optaron por el sistema de entrevistas telefónicas asistidas por computador (CATI, por su nombre en inglés) cuando la penetración de la telefonía fija en la población chilena era inferior al 70 por ciento. Hoy, la cobertura de la telefonía móvil supera el 
100 por ciento, a pesar de que este dato está sesgado por nivel socioeconómico, al igual que en muchos otros países.

Considerando el cambio en el sistema electoral, además de estos temas históricos sobre modo y cobertura geográfica, no es sorprendente que las encuestas preelectorales en Chile hayan tenido problemas de estimación en la elección presidencial de 2013. Esta fue la primera convocatoria de carácter nacional en la cual se pasó de la inscripción voluntaria y el voto obligatorio a la inscripción obligatoria y el voto voluntario. Era la primera vez que los consejeros regionales eran elegidos por sufragio universal. Michelle Bachelet era una candidata presidencial muy conocida, que ya había ejercido como Presidenta y que era muy popular entre el electorado. Su oponente, Evelyn Matthei, era la tercera candidata de su coalición, que fue escogida relativamente tarde en el proceso debido a la renuncia de dos candidatos anteriores. A pesar de tener mucha experiencia en campañas políticas, nunca antes había postulado a la presidencia e inició su campaña con una desventaja en términos de reconocimiento público. Más aún, tenía posiciones diametralmente opuestas en tres temas en los que el público y Bachelet estaban a favor (Bunker 2014).

Con el nuevo sistema electoral, se esperaba una baja en la participación, lo que se confirmó en los hechos y de manera significativa. Las encuestas preelectorales no permitían predecir claramente si Bachelet ganaría en la primera vuelta, lo que finalmente no sucedió. Pero su liderazgo permanente en las encuestas de primera vuelta produjo un cambio en la cobertura periodística y un énfasis en las elecciones legislativas. En la primera vuelta, Bachelet obtuvo una ventaja de 20 puntos porcentuales, que equivalían a una diferencia de aproximadamente 1,5 millones de votos, a pesar de que superó, en general, las estimaciones entregadas por las encuestas preelectorales. Los resultados también sugirieron que se había producido algún grado de voto estratégico y que los ciudadanos habían abandonado a algunos de los candidatos rivales para favorecer a Matthei. En la segunda vuelta presidencial, Bachelet recibió el mayor porcentaje y menor número de votos de cualquier candidato presidencial ganador en recientes elecciones, incluida su propia victoria de 2005. Las escasas encuestas preelectorales indicaban una victoria holgada para Bachelet y la participación se mantuvo baja.

En esas condiciones, la cantidad de encuestas realizadas antes de cada vuelta electoral disminuyó en relación con comicios anteriores. 
Las empresas de opinión tuvieron que desarrollar nuevos modelos de participación a la luz de la baja esperada, producto del nuevo sistema electoral, del amplio margen obtenido por Bachelet en la primera vuelta electoral y de los resultados de las encuestas previas a la segunda vuelta. El modelo de votante probable tuvo que ser también revisado, ya que era casi una certeza que la composición del electorado cambiaría en relación con las características de la población general. De hecho, todos esos factores incidieron en los algoritmos de ponderación. Esto fue una tarea ardua para los encuestadores en dos aspectos. Primero, la calibración de un buen modelo de participación implica la comparación de respuestas de encuestas con registros sobre comportamiento real del voto a través de estudios de validación; sin embargo, estos estudios aún no son legales en Chile. Segundo, este trabajo se beneficiaría con investigaciones en que los encuestados antes de las elecciones fueran entrevistados con posterioridad a los comicios para confirmar si fueron a votar o mantuvieron sus preferencias de candidato iniciales. En la actualidad estos datos tampoco están disponibles en Chile.

Puesto que las empresas que hacen estudios de opinión no entregan detalles sobre participación, composición del electorado y modelos de votante probable, ésta es un área que requiere mayor transparencia. También se produjo una transición hacia un nuevo modo de encuesta cuando dos empresas adoptaron las entrevistas telefónicas en lugar de las presenciales, como las restantes; éstas arrojaron márgenes relativamente modestos para Bachelet en la primera vuelta. Sólo una realizó una encuesta preelectoral telefónica en la segunda vuelta y sobreestimó el margen de Bachelet, como suele suceder en elecciones muy desiguales, donde puede darse un voto táctico (Fisher 2001). Esta es otra razón para reexaminar la metodología de encuestas en Chile.

Si se consideran en términos generales los problemas que las empresas de sondeos preelectorales han debido enfrentar en otros países y circunstancias, estas situaciones comunes ameritan estudios adicionales a la luz de la nueva normativa electoral en Chile. Los problemas comunes pueden ser abordados con soluciones comunes, tomando en cuenta las características del sistema político y social de Chile. El desarrollo de soluciones requerirá la colaboración entre académicos y centros de sondeo comerciales, no sólo de Chile, sino que también de aquellos que estudian los métodos y las encuestas preelectorales en todo el mundo. 
Para lograr soluciones se requiere un intercambio amplio de información, práctica no muy usual entre la mayoría de las empresas de sondeo. Pero, de realizarse, ella se traducirá en una mejora en los métodos de encuesta preelectoral y, por tanto, en la imagen de la industria en Chile.

\section{CONCLUSIONES}

Las encuestas preelectorales son un importante componente de la difusión mediática moderna de las elecciones. También desempeñan un rol relevante en darle al público una voz en el diseño de nuevas leyes y políticas mediante la difusión de sus preferencias y los niveles de información que el público tiene sobre esos temas. También orientan a los candidatos y partidos sobre el desarrollo de sus agendas políticas en términos de preferencias del público y su tolerancia al cambio. El acierto en las encuestas preelectorales contribuye a reforzar la posición de las empresas de sondeos de opinión e investigación de mercado, debido a la estrecha relación que tienen sus predicciones finales con el resultado real de la contienda electoral durante la cual fueron realizadas. En términos generales, la calidad de las encuestas en las elecciones nacionales ha mejorado a lo largo del tiempo a través del desarrollo de nuevos métodos, que permiten aprovechar las nuevas tecnologías y hacer frente a las presiones por reducir costos en la recopilación de datos.

En todo el mundo surgen periódicamente problemas con las encuestas preelectorales y es tarea de los académicos y críticos de los medios de comunicación solucionarlos y dilucidar las causas posibles de estos errores. Se requiere mayor colaboración entre las empresas captadoras de datos y los diseñadores independientes de metodologías de encuesta a fin de resolver esos problemas, y para ello es primordial, en primer lugar, obtener información sobre los métodos utilizados en la actualidad. Tanto la Asociación Estadounidense para la Investigación de la Opinión Pública (AAPOR, por su nombre en inglés) como la Asociación Mundial para la Investigación de la Opinión Pública (WAPOR, por su nombre en inglés) cuentan con estándares para la difusión de dicha información. La solución para resolver los problemas recurrentes que afectan a las encuestas es una mayor transparencia por parte de los encuestadores y una revisión constante y minuciosa de sus métodos en relación con la exactitud de sus resultados. 
La técnica estándar para asegurar la calidad de los métodos utilizados en las encuestas preelectorales y aprender más sobre las características del electorado es realizar estudios de validación después de las elecciones (Abelson et al. 1992; Belli et al. 2001; Traugott y Katosh 1979). En ese tipo de investigación, la situación declarada por los entrevistados en términos de su inscripción y comportamiento de voto es cotejada con datos oficiales en las oficinas electorales. Las iniciativas de validación en Chile aún son ilegales cuando son realizadas por investigadores no gubernamentales. La forma de enfrentar este problema es organizar iniciativas conjuntas entre el gobierno, los investigadores académicos y las empresas de estudios de opinión, en las cuales se diseña y se prueba en terreno una muestra en una encuesta preelectoral que incorpore una serie de hipótesis verificables sobre diseño de muestra y de cuestionario. Después de la elección y cuando los datos relevantes han sido actualizados, los funcionarios estatales pueden realizar una verificación de los datos de inscripción y de sufragio. Luego la información puede vincularse con los datos globales de la encuesta, una vez que se han tomado los debidos resguardos para velar por la confidencialidad y anonimato del análisis por parte de múltiples investigadores, con o sin supervisión gubernamental.

Este tipo de investigación permitirá preservar la confianza del público en las encuestas y de aquellos que las utilizan para medir las fluctuaciones de la opinión pública. Los académicos y los profesionales comparten un mismo objetivo: diseñar y aplicar los mejores métodos para obtener los datos más exactos en las condiciones estándares que enfrentan los encuestadores. Por esa vía, el público general, así como el más especializado, se sentirá confiado en la calidad de los datos recopilados y difundidos a través de los medios de comunicación, así como en la transmisión de su preferencia y preocupaciones políticas a los representantes electos.

\section{REFERENCIAS CITADAS}

Abelson, Robert P., Elizabeth F. Loftus \& Anthony G. Greenwald. 1992. "Attempts to Improve the Accuracy of Self-Reports of Voting." En Questions about Questions, editado por Judith M. Tanur. Nueva York: Russell Sage Foundation.

American Association for Public Opinion Research (AAPOR). 2009. "An Evaluation of the Methodology of the 2008 Pre-election Primary Polls." 
AAPOR Task Force Report. http://www.aapor.org/AM/Template. cfm?Section=Reports $1 \&$ Template=/CM/ContentDisplay.cfm\&ContentID=3867/

- 2010. "New Considerations for Survey Researchers When Planning and Conducting RDD Telephone Surveys in the U.S. With Respondents Reached via Cell Phone Numbers.” AAPOR Task Force Report. http://www.aapor.org/ Cell_Phone_Task_Force_Report.htm\#.U0_-FFdMxBA/

—. 2013. "Report of the AAPOR Task Force on Non-Probability Sampling." AAPOR Task Force Report. http://www.aapor.org/AAPORKentico/AAPOR_ Main/media/MainSiteFiles/NPS_TF_Report_Final_7_revised_FNL_6_22_13. pdf/

Astudillo, Juan Diego, Scott Clement, Heather Hicks, Carlos Macuado \& Michael Sadowsky. 2014. "Which Likely Voter Model Is Best? Relative Accuracy of Likely Voter Models in the 2013 Virginia and New Jersey Governor's Elections." Ponencia presentada en la conferencia anual de la AAPOR, Anaheim.

Belli, Robert F., Michael W. Traugott \& Matthew Beckmann. 2001. "What Leads to Vote Overreports: Contrasts of Overreporters to Validated Voters and Admitted Nonvoters in the American National Election Studies." Journal of Official Statistics 17: 479-98.

Bethlehem, Jelke. 2010. "Selection Bias in Web Surveys." International Statistical Review 78: 161-88.

Blumberg, Stephen J. \& Julian V. Luke. 2014. "Wireless Substitution: Early Release of Estimates from the National Health Interview Survey, July-December 2013." U.S. Department of Health and Human Services, Centers for Disease Control and Prevention, National Center for Health Statistics. http://www.cdc. gov/nchs/data/nhis/earlyrelease/wireless201407.pdf/

Bunker, Kenneth. 2014. "The 2013 Presidential and Legislative Elections in Chile." Electoral Studies 34: 346-48.

Chaffee, Steven H. 2000. "George Gallup and Ralph Nafziger: Pioneers of Audience Research." Mass Communication and Society 3: 317-327.

Clawson, Rosalee A. \& Zoe M. Oxley. 2012. Public Opinion: Democratic Ideals, Democratic Practice. Washington: CQ Press.

Curtin, Richard, Stanley Presser \& Eleanor Singer. 2000. "The Effects of Response Rate Changes on the Index of Consumer Sentiment." Public Opinion Quarterly 64: 413-28.

De Leeuw, Edith \& Wim de Heer. 2002. "Trends in Household Survey Nonresponse: A Longitudinal and International Comparison.” En Survey Nonresponse, editado por Robert M. Groves, Don A. Dillman, John L. Eltinge y Roderick J. A. Little. Nueva York: John Wiley \& Sons.

DelReal, José. 2014. "Voter Turnout in 2014 Was the Lowest since WWII." Washington Post, 10 de noviembre. http://www.washingtonpost.com/blogs/ post-politics/wp/2014/11/10/voter-turnout-in-2014-was-the-lowest-sincewwii/

Durand, Claire. 2010. "Why Do Polls Go Wrong Sometimes?" Ponencia presentada en la conferencia anual de la AAPOR, Chicago. http://www.mapageweb. 
umontreal.ca/durandc/Recherche/Publications/pollsgowrong/pollsgowrong aapor2010.pdf/

- 2011. "Polls at the Subnational Level: The Canadian Case." Ponencia presentada en la conferencia anual de la WAPOR, Amsterdam. http:// www.mapageweb.umontreal.ca/durandc/Recherche/Publications/elecqc/ Amsterdam_Wapor2011_durandc.pdf/

Eisenstein, Maurice M. \& Marie A. Wittig. 2000. "Time and the Life Cycle of Presidential Approval: A Research Note.” Social Science Journal 37: 27-42.

Erikson, Robert \& Christopher Wlezien. 2012. The Timeline of Presidential Elections: How Campaigns Do (and Don't) Matter. Chicago: University of Chicago Press.

Fisher, Stephen. 2001. "Tactical Voting and Tactical Non-Voting." Centre for Research Into Elections and Social Trends, Working Paper 93. http://www. crest.ox.ac.uk/papers/p93.pdf/

Gallup. 2013. "Gallup 2012 Presidential Election Polling Review.” http:/www. gallup.com/file/poll/162887/Gallup\%202012\%20Presidential\%20Election $\% 20$ Polling\%20Review.pdf/

Gallup, George \& Saul F. Rae. 1940. The Pulse of Democracy. Nueva York: Simon and Schuster.

Gelman, Andrew. 2013. "A Poll Is a Snapshot, Not a Forecast." The Washington Post, 13 de octubre. http://www.washingtonpost.com/blogs/monkey-cage/ wp/2013/12/10/a-poll-is-a-snapshot-not-a-forecast/

Grossman, Michael Baruch \& Martha Joynt Kumar. 1981. Portraying the President. Baltimore, MD: Johns Hopkins University Press.

Groves, Robert. 2006. "Nonresponse Rates and Nonresponse Bias in Household Surveys.” Public Opinion Quarterly 70: 646-75.

Groves, Robert \& Lars Lyberg. 2010. "Total Survey Error: Past, Present, and Future.” Public Opinion Quarterly 74 (5): 849-879.

Herbst, Susan. 1993. Numbered Voices: How Opinion Polling Has Shaped American Politics. Chicago: University of Chicago Press.

Iyengar, Shanto, Helmut Norpoth \& Kiyu S. Hahn. 2004. "Consumer Demand for Election News: The Horserace Sells.” Journal of Politics 66: 157-75.

Keeter, Scott. 2006. "The Impact of Cell Phone Noncoverage Bias on Polling in the 2004 Presidential Election.” Public Opinion Quarterly 70: 88-98.

Keeter, Scott, Carolyn Miller, Andrew Kohut, Robert Groves \& Stanley Presser. 2000. "Consequences of Reducing Nonresponse in a National Telephone Survey.” Public Opinion Quarterly 64: 125-48.

Kennedy, Courtney. 2007. "Evaluating the Effects of Screening for Telephone Service in Dual Frame RDD Surveys." Public Opinion Quarterly 71: 750-71.

Kim, Sunwoong, Michael W. Traugott, So Hyung Park \& Sang Kyung Lee. 2011. "Why Did the Pre-election Polls in South Korean Local Elections Go All Wrong? Assessing the Source of Errors Using Dual Frame Landline / Cell Phone Post-Election Survey." Ponencia presentada en la conferencia anual de la WAPOR, Amsterdam. 
Lavrakas, Paul J. \& Michael W. Traugott. 2000. "Why Election Polls Are Important to Democracy: An American Perspective." En Election Polls, the News Media, and Democracy, editado por Lavrakas y Traugott. Nueva York: Chatham House Publishers.

Levine, Burton \& Rachel Harter. Por publicarse. "Optimal Allocation of CellPhone and Landline Respondents in Dual-Frame Surveys." Public Opinion Quarterly. http://poq.oxfordjournals.org/content/early/2014/10/28/poq.nfu044. full.pdf+html?sid=19b3f567-cdae-4884-8bfe-dc26e9ae5bc6/

Likert, Rensis. 1948. "The Polls: Straw Votes or Scientific Instruments." American Psychologist 3: 556-57.

Martin, Elizabeth, Michael W. Traugott \& Courtney Kennedy. 2005. "A Review and Proposal for a New Measure of Poll Accuracy.” Public Opinion Quarterly 69: 342-69.

McClain, Colleen \& Maura Spiegelman. 2014. "Understanding Measurement Error in Vote Recall and Vote Intention: Question Wording Experiments in 2013 Virginia and New Jersey Gubernatorial Polling." Ponencia presentada en la conferencia anual de la AAPOR, Anaheim.

Merkle, Daniel \& Murray Edelman. 2002. "Nonresponse in Exit Polls: A Comprehensive Analysis." En Survey Nonresponse, editado por Robert M. Groves, Don A. Dillman, John L. Eltinge y Roderick J. A. Little, 243-58. Nueva York: John Wiley \& Sons.

Moreno, Alejandro. 2009. "Encuestas y elecciones en México: La precisión de estimaciones preelectorales en un contexto de cambio." Ponencia presentada en el segundo congreso latinoamericano de la WAPOR, Lima.

—. 2010. "Las fallas de las encuestas." Diario Reforma, sección Enfoque, 25 de julio.

Moreno, Alejandro, Rosario Aguilar \& Vidal Romero. 2012. "La precisión de las encuestas electorales en México: un análisis de las fuentes de error." Revista Legislativa de Estudios Sociales y de Opinión Pública 4 (8): 7-45.

Mosteller, Frederick, Herbert Hyman, Phillip J. McCarthy, Eli S. Marks \& David B. Truman. 1949. The Pre-election Polls of 1948: Report to the Committee on Analysis of Pre-election Polls and Forecasts. Nueva York: Social Science Research Council.

Mueller, John. 1970. "Presidential Popularity from Truman to Johnson." American Political Science Review 64: 18-34.

Navia, Patricio. 2003. "Public Opinion Polls in Chile." En Public Opinion and Polling Around the World: A Historical Encyclopedia, editado por John G. Geer. Santa Barbara, CA: ABC-CLIO.

Patterson, Thomas E. 1993. Out of Order. Nueva York: Alfred A. Knopf.

—. 2005. "Of Polls, Mountains: U.S. Journalists and Their Use of Election Surveys.” Public Opinion Quarterly 69: 716-24.

Pew Research Center. 2010. "Cell Phones and Election Polls." http://www. pewresearch.org/2010/10/13/cell-phones-and-election-polls-an-update/ 
—. 2013. "Cell Phones.” http://www.people-press.org/methodology/sampling/ cell-phones/

Pillsbury, George \& Julian Johannsen. 2013. America Goes to the Polls 2012. Boston: NonprofitVote. http://www.nonprofitvote.org/documents/2013/03/ america-goes-to-the-polls-2012.pdf/

Public Opinion Quarterly. 2010. "Special Issue: Total Survey Error.” 74 (5): 8171045.

Rivers, Doug. 2014. "YouGov Poll Performance in the 2014 Senate Elections." YouGov Us, noviembre 5. https://today.yougov.com/news/2014/11/05/yougovpoll-performance-2014-senate-elections/

Rosenstiel, Thomas. 2005. "Political Polling and the New Media Culture: A Case of More Being Less.” Public Opinion Quarterly 69: 698-715.

Rothschild, David \& Doug Rivers. 2012. "Snapshots and Movies: Most Polls Are Snapshots, but the Xbox / YouGov Panel Shows Voters in Motion." Huffpost Pollster, octubre 22. http://www.huffingtonpost.com/david-rothschild/mostpolls-are-snapshots_b_2003394.html/

Silver, Nate. 2014. "The Polls Were Skewed Toward Democrats." Five Thirty Eight, 13 de octubre. http://fivethirtyeight.com/features/the-polls-were-skewedtoward-democrats/

Squire, Peverill. 1988. "Why the 1936 The Literary Digest Poll Failed." Public Opinion Quarterly 52: 125-33.

Toepoel, Vera, Marcel Das \& Arthur Van Soest. 2008. "Effects of Design in Web Surveys: Comparing Trained and Fresh Respondents." Public Opinion Quarterly 72: 985-1007.

Traugott, Michael W. 1992. "The Impact of Media Polls on the Public." En Media Polls in American Politics, editado por Thomas E. Mann y Gary R. Orren. Washington: The Brookings Institution: 125-149.

— 2004. "Do Polls Give the Public a Voice in Democracy?" En Polls and Politics: The Dilemmas of Democracy, editado por Michael A. Genvoese y Matthew J. Streb. Albany: State University of New York Press.

— 2012. "Data Quality from Low Cost Data Collection Methodologies." Ponencia presentada en la conferencia anual de la AAPOR, Orlando, FL.

—. 2015. "Métodos alternativos para la estimación de resultados electorales." Estudios Públicos 137: 7-42.

Traugott, Michael W. \& John P. Katosh. 1979. "Response Validity in Surveys of Voting Behavior.” Public Opinion Quarterly 43: 359-77.

Traugott, Michael W. \& Chris Wlezien. 2009. "The Dynamics of Poll Performance during the 2008 Presidential Nomination Contest." Public Opinion Quarterly 73: 866-94.

Wang, Sam. 2014. "Midterm National Senate Polling Error Is Five Times Larger Than in Presidential Years." Princeton Election Consortium, octubre 17. http:// election.princeton.edu/2014/10/17/is-ebola-diverting-voter-attention/ 
Yen, Hope. 2013. "Black Voter Turnout Passes Whites in 2012 Election, A First In Census History." Huffpost Politics, mayo. http://www.huffingtonpost. com/2013/05/08/black-voter-census_n_3240403.html/EP 